Original Article

\title{
Effect of a virtual reality exercise program accompanied by cognitive tasks on the balance and gait of stroke patients
}

\author{
In-Wook Lee, MSc ${ }^{1)}$, Yong-Nam Kim, PhD²*, Dong-Kyu Lee, MSc ${ }^{3)}$ \\ 1) Department of Physical Therapy, Graduate School, Nambu University, Republic of Korea \\ 2) Department of Physical Therapy, Nambu University: 861-1 Wolgye-dong, Gwangsan-Gu, Gwangju, \\ Republic of Korea \\ 3) Department of Rehabilitation Science, Graduate School, Daegu University, Republic of Korea
}

\begin{abstract}
Purpose] This study aimed to assess the effect of a virtual reality exercise program accompanied by cognitive tasks on the balance and gait of stroke patients. [Subjects] Twenty stroke patients were randomly assigned to two groups 10 to an experimental group that performed a virtual reality exercise program accompanied by cognitive tasks and 10 to a control group. The control group performed a proprioceptive neuromuscular facilitation exercise program. Balance was measured with the Berg Balance Scale. Gait was assessed using the Timed Up and Go Test. The paired t-test was used to compare groups before and after the experiment. The independent t-test was conducted to assess differences in the degree of change between the two groups before and after the experiment. [Results] Within-group comparison in the experimental group showed significant differences in the Berg Balance Scale and Timed Up and Go Test. In a comparison between groups, the differences in the Berg Balance Scale and Timed Up and Go Test in the experimental group appeared significant compared with the control group. [Conclusion] The results of the experiment indicate that a virtual reality exercise program accompanied by cognitive tasks has a positive effect on the balance and gait of stroke patients.

Key words: Virtual reality exercise program accompanied by cognitive tasks, Balance, Gait
\end{abstract}

(This article was submitted Feb. 27, 2015, and was accepted Apr. 3, 2015)

\section{INTRODUCTION}

Stroke occurs when vessels supplying blood to the brain are damaged or blocked, resulting in disorders of movement, sensation, perception, cognition, and language, depending on the area damaged ${ }^{1)}$. Impaired mobility after stroke causes body imbalance and hemiplegia, that is paralysis on either left or right side of the body ${ }^{2}$. Hemiplegia results in asymmetric posture and abnormal balance that cause decreased ability in weight translation and gait ${ }^{3}$. Impairment in gait and balance ability leads to limited movement and injuries from falls in stroke patients; recovering these two functions is regarded as the chief objective in stroke rehabilitation ${ }^{3,4)}$.

Cognition is the ability to understand phenomena in everyday life, process received information, and take action. It ranges from basic functions, such as concentration and memory, to higher-level functions consisting of planning, organizing, problem-solving, calculating, and abstract thinking abilities ${ }^{5)}$. Cognitive task exercise is a method

*Corresponding author. Yong-Nam Kim (E-mail: kyn5441@hanmail.net)

(C2015 The Society of Physical Therapy Science. Published by IPEC Inc. This is an open-access article distributed under the terms of the Creative Commons Attribution Non-Commercial No Derivatives (by-ncnd) License $<$ http://creativecommons.org/licenses/by-nc-nd/3.0/> . of recovering function through repetitious training ${ }^{6}$. On the assumption that reorganization would occur to replace functions of a damaged brain part, this training improves memory, attention, and cognitive abilities through number and word memorization ${ }^{5,6}$. Recently, cognitive and physical task exercises have been applied in stroke patients for physical rehabilitation ${ }^{7,8)}$.

With advanced scientific technology, treatment methods based on virtual reality with a simulated environment and activities have been adopted ${ }^{9,10)}$. Virtual reality is an interactive simulation designed to give users an experience similar to the real world through computer hardware and software ${ }^{10)}$. It allows users to perform given tasks and effectively control movements through interaction with various types of feedback ${ }^{11)}$. Thus, it induces a sense of reality and enables persistent and active exercise ${ }^{10,11)}$. Virtual reality exercise programs are reported to improve the balance and gait of stroke patient ${ }^{12,13)}$.

Many studies using virtual reality exercise programs have been reported ${ }^{9-13)}$. However, there are few studies on the effect of virtual reality exercise programs accompanied by cognitive tasks in stroke patients. The aim of this was to assess the effect of a virtual reality exercise program accompanied by cognitive tasks on the balance and gait of stroke patients. 


\section{SUBJECTS AND METHODS}

The subjects of this research were 20 patients who were diagnosed with stroke; based on computed tomography (CT) and magnetic resonance imaging (MRI) results more than six months prior, understood the research purpose, and agreed to participate in the experiments. Participants were randomly assigned to two groups: 10 (6 males and 4 females) to an experimental group, which performed a virtual reality exercise program accompanied by cognitive tasks, and another 10 ( 5 males and 5 females) to a control group. All subjects scored over 24 points on the Mini-Mental State Examination (MMSE), could independently walk over 10 meters, could acknowledge understanding of instructions and communication, and had no visual impairment, visual field defects, or orthopedic disease. All participants were informed about the research purpose and provided informed consent before the experiment. The study protocol was approved by the Institutional Review Board of Nambu University and was conducted in accordance with the ethical principles of the Declaration of Helsinki. The overall condition of the subjects was as shown in Table 1. For the experimental group, age, height and weight were $57.2 \pm 9.2$ years, $160.2 \pm 11.2 \mathrm{~cm}$, and $65.2 \pm 10.5 \mathrm{~kg}$, respectively. For the control group, age height and weight were $52.7 \pm 11.7,162.2 \pm 12.4 \mathrm{~cm}$, and $64.7 \pm 11.7 \mathrm{~kg}$, respectively.

The virtual reality exercise program assigned to the experimental group included simultaneous cognitive tasks in virtual reality space. The virtual reality exercise program used the city walking (left-right weight shift), hot air balloon (up-down weight shift), and bubble (total weight shift) activities available in BioRescue (RM Ingénierie, Rodez, France). BioRescue has a $610 \times 580 \times 10 \mathrm{~mm}$ platform and a total 1,600 pressure sensors. Each subject stood on the BioRescue platform and maintained their balance by shift-

Table 1. General characteristics of the subjects

\begin{tabular}{lcc}
\hline & EG $(\mathrm{n}=10)$ & $\mathrm{CG}(\mathrm{n}=10)$ \\
\hline Gender (male/female) & $6 / 4$ & $5 / 5$ \\
Paretic side (right/left) & $6 / 4$ & $7 / 3$ \\
Age (years) & $57.2 \pm 9.2$ & $52.7 \pm 11.7$ \\
Weight (kg) & $65.2 \pm 10.5$ & $64.7 \pm 11.7$ \\
Height (cm) & $160.2 \pm 11.2$ & $162.2 \pm 12.4$ \\
\hline
\end{tabular}

${ }^{\mathrm{a}} \mathrm{Mean} \pm$ SD. EG: experimental group; CG: control group ing their weight while watching a monitor. As a cognitive task, addition and subtraction by tens; and backward reading of two or three words or numbers were added. To avoid a learning effect while performing cognitive tasks, subjects randomly chose slips of paper on which cognitive tasks were written. The control group performed a proprioceptive neuromuscular facilitation (PNF) exercise program. PNF exercises included D (diagonal) 1 and D2 patterns for the lower limbs. D1 patterns are hip joint flexion, hip joint adduction, hip joint external rotation, and knee joint flexion, and then hip joint extension, hip joint abduction, hip joint internal rotation and knee joint extension. D2 patterns are hip joint flexion, hip joint abduction, hip joint internal rotation and knee joint flexion and then hip joint extension, hip joint adduction, hip joint external rotation and knee joint extension. Both exercise programs for the experimental and control groups were performed 45 minutes a day, 3 times a week, for 6 weeks.

Balance was measured by the Berg Balance Scale (BBS). The BBS is divided into three sections, including sitting, standing, and changing posture, and scores 14 items to evaluate balance ability objectively. The score ranges from 0 to 4 , and the total score is up to 56 points. Higher scores indicate good balancing ability. Gait was measured using the Timed Up and Go Test (TUGT), which estimates functional mobility. In the TUGT, the time required for a subject sitting on an armchair to stand up when signaled, walk $3 \mathrm{~m}$, and return to the armchair and sit down is measured.

Collected data were statistically processed using SPSS 12.0 (SPSS, Chicago, IL, USA) for Windows. Subjects' overall characteristics were evaluated by descriptive statistics. The paired t-test was used to compare groups before and after the experiment. The independent t-test was conducted to assess differences in the degree of change between the two groups before and after the experiment. The significance level was set to $\alpha=0.05$.

\section{RESULTS}

The changes in BBS and TUGT are as shown in Table 2. Within-group comparison in the experimental group showed significant differences in BBS and TUGT $(\mathrm{p}<0.05)$. In a comparison between groups, the differences in BBS and TUGT of the experimental group appeared significant compared with the control group $(\mathrm{p}<0.05)$.

Table 2. Comparison of the results of the BBS and TUGT between the experimental and control groups

\begin{tabular}{lcccc}
\hline & Group & Pre & Post & D-Value \\
\hline BBS (score) & EG & $37.8 \pm 2.2$ & $46.2 \pm 2.3^{*}$ & $8.4 \pm 2.5^{\#}$ \\
& CG & $38.6 \pm 1.3$ & $41.5 \pm 3.7$ & $2.9 \pm 4.3$ \\
\multirow{2}{*}{ TUGT (sec) } & EG & $21.2 \pm 2.9$ & $13.6 \pm 0.9^{*}$ & $-7.6 \pm 2.5^{\#}$ \\
& CG & $22.1 \pm 2.1$ & $18.3 \pm 1.4$ & $-3.8 \pm 2.2$ \\
\hline
\end{tabular}

${ }^{a}$ Mean \pm SD. ${ }^{*} p<0.05$ (paired t-test). ${ }^{\#} p<0.05$ (independent t-test). D-value: difference value; EG: experimental group; CG: control group; BBS: Berg Balance Scale; TUGT: Timed Up and Go Test 


\section{DISCUSSION}

The aim of this study was to assess the effects of a virtual reality exercise program accompanied by cognitive tasks on the balance and gait of stroke patients. The experimental group showed a significant difference in BBS in the withingroup comparison. In a comparison between groups, the BBS score of the experimental group was significantly improved compared with the control group. According to a study by Liorens et al. ${ }^{12)}$, an experimental group of chronic stroke patients treated with virtual reality exercise showed significant improvement in the BBS. McEwen et al. ${ }^{13)}$ reported that balance ability was meaningfully improved when an experimental group of 59 stroke patients performed virtual reality exercises. Research by An et al. ${ }^{7)}$ showed that, as a result of performing cognitive and physical tasks, an experimental group of 18 stroke patients had significantly improved balance relative to that of a control group. A virtual reality exercise program provides motivation and visual, auditory, and tactile feedback, which aids in active movement and balance ${ }^{9,10)}$. Thus, it induces proprioceptive stimulation from the vestibular system and improves balance ability ${ }^{10,11)}$. Also, repeated performance of cognitive and physical tasks improves concentration during both tasks ${ }^{7,8)}$. This increase in concentration during cognitive tasks could help increase concentration during physical tasks; and could have a positive effect on balance. Prior research and this study prove that a virtual reality exercise program with cognitive tasks positively affects the balance ability of stroke patients.

Gait is the fundamental motion for body transfer; and requires continuous and repetitive movement of each segment for functional walking ${ }^{14)}$. The asymmetric gait tendency exhibited by stroke patients cause difficulty in independent walking ${ }^{15)}$. In this research on the change in gait, the TUGT of the experimental group showed significant differences in a within-group comparison. In comparison between groups, the TUGT results of the experimental group were significantly improved compared with the control group. McEwen et al. ${ }^{13)}$ reported that use of virtual reality exercises for stroke patients had a positive effect on gait ability. In a study by Jung et al. ${ }^{8)}$, use of both cognitive and physical tasks for stroke patients resulted in gait improvement. Research by An et al. ${ }^{7}$ showed that a group of chronic stroke patients that performed cognitive and physical tasks had improved gait. The results of prior research and this study are consistent. A virtual reality exercise program accompanied by cognitive tasks improved stroke patients' balance and gait ability.

This research has a limitation with respect to generalization on the findings to all stroke patients, since it was conducted in a small group. In addition, follow-up was not performed, so the duration of the effect is unknown. Further study is needed with a larger number of patients for a longer time period of follow-up.

\section{REFERENCES}

1) Mahabir D, Bickram L, Gulliford MC: Stroke in Trinidad and Tobago: burden of illness and risk factors. Rev Panam Salud Publica, 1998, 4: 233-237. [Medline] [CrossRef]

2) Ikai T, Kamikubo T, Takehara I, et al.: Dynamic postural control in patients with hemiparesis. Am J Phys Med Rehabil, 2003, 82: 463-469, quiz 470-472, 484. [Medline] [CrossRef]

3) Carr JH, Shepherd RB, Nordholm L, et al.: Investigation of a new motor assessment scale for stroke patients. Phys Ther, 1985, 65: 175-180. [Medline]

4) Belda-Lois JM, Mena-del Horno S, Bermejo-Bosch I, et al.: Rehabilitation of gait after stroke: a review towards a top-down approach. J Neuroeng Rehabil, 2011, 8: 66. [Medline] [CrossRef]

5) Campbell AJ, Borrie MJ, Spears GF, et al.: Circumstances and consequences of falls experienced by a community population 70 years and over during a prospective study. Age Ageing, 1990, 19: 136-141. [Medline] [CrossRef]

6) Ben-Yishay Y, Diller L: Cognitive remediation in traumatic brain injury: update and issues. Arch Phys Med Rehabil, 1993, 74: 204-213. [Medline]

7) An HJ, Kim JI, Kim YR, et al.: The effect of various dual task training methods with gait on the balance and gait of patients with chronic stroke. J Phys Ther Sci, 2014, 26: 1287-1291. [Medline] [CrossRef]

8) Jung K, Kim Y, Chung Y, et al.: Weight-shift training improves trunk control, proprioception, and balance in patients with chronic hemiparetic stroke. Tohoku J Exp Med, 2014, 232: 195-199. [Medline] [CrossRef]

9) Zhang L, Abreu BC, Masel B, et al.: Virtual reality in the assessment of selected cognitive function after brain injury. Am J Phys Med Rehabil, 2001, 80: 597-604, quiz 605. [Medline] [CrossRef]

10) Chan CL, Ngai EK, Leung PK, et al.: Effect of the adapted virtual reality cognitive training program among Chinese older adults with chronic schizophrenia: a pilot study. Int J Geriatr Psychiatry, 2010, 25: 643-649. [Medline]

11) Rizzo AA, Buckwalter JG: Virtual reality and cognitive assessment and rehabilitation: the state of the art. Stud Health Technol Inform, 1997, 44: 123-145. [Medline]

12) Lloréns R, Gil-Gómez JA, Alcañiz M, et al.: Improvement in balance using a virtual reality-based stepping exercise: a randomized controlled trial involving individuals with chronic stroke. Clin Rehabil, 2015, 29: 261-268. [Medline] [CrossRef]

13) McEwen D, Taillon-Hobson A, Bilodeau M, et al.: Virtual reality exercise improves mobility after stroke: an inpatient randomized controlled trial. Stroke, 2014, 45: 1853-1855. [Medline] [CrossRef]

14) Roerdink M, Lamoth CJ, Kwakkel G, et al.: Gait coordination after stroke: benefits of acoustically paced treadmill walking. Phys Ther, 2007, 87: 1009-1022. [Medline] [CrossRef]

15) Dias D, Laíns J, Pereira A, et al.: Can we improve gait skills in chronic hemiplegics? A randomised control trial with gait trainer. Eura Medicophys, 2007, 43: 499-504. [Medline] 